\title{
Mifepristone was more effective than the Yuzpe regimen for emergency contraception
}

\author{
Ashok PW, Stalder C, Wagaarachchi PT, et al. A randomised study comparing a low dose of mifepristone and the Yuzpe \\ regimen for emergency contraception. BJOG 2002;109:553-60.
QUESTIONS: In women seeking emergency contraception, is low dose mifepristone more effective than the Yuzpe regimen in preventing pregnancies? Does it have fewer side effects and better patient acceptability?

\section{Design}

Randomised (allocation concealed), unblinded, controlled trial. Women were followed up for 2 weeks after the expected next menstrual period. Women who were not pregnant were followed up until their next period.

\section{Setting}

A family planning clinic in Aberdeen, Scotland.

\section{Patients}

1000 women between 16 and 45 years of age seeking emergency contraception within 72 hours after an episode of unprotected sexual intercourse who had regular menstrual cycles (21-35 d), were certain about the dates of their last menstrual period, and were willing to abstain from further acts of unprotected intercourse during the menstrual cycle. Exclusion criteria were use of oral contraceptives or hepatic enzyme inducing drugs, chronic adrenal failure, long term corticosteroid treatment, breast feeding, allergy, or contraindications to mifepristone or to oestrogen and progestogen. Women certain to continue with pregnancy if emergency contraception failed were also excluded. 958 women $(96 \%)$ (mean age 22.5 y) had complete follow up.

\section{Intervention}

500 women were allocated a single dose of mifepristone, $100 \mathrm{mg}$, and 500 were allocated to the Yuzpe regimen (2 tablets each with ethinyloestradiol, $50 \mu \mathrm{g}$, and levonorgestrel, $0.25 \mathrm{mg}$, repeated $12 \mathrm{~h}$ later).

\section{Main outcome measures}

Crude pregnancy rates, rates of prevented pregnancies, side effects, and patient acceptability.

\section{Main results}

Analysis was by intention to treat. Mifepristone was more effective than the Yuzpe regimen for preventing pregnancies (table). Mifepristone prevented 36 of 39 expected pregnancies (92\%) and the Yuzpe regimen prevented 22 of 39 expected pregnancies $(56 \%)$ $\{\mathrm{p}<0.001\}$. Overall, mifepristone was better tolerated than the Yuzpe regimen. More women were satisfied with mifepristone than with the Yuzpe regimen $(p<0.001)$. However, information about side effects and patient acceptability was only reported by $62 \%$ of participants.
For correspondence:

Dr P W Ashok

Department of

Gynaecology, University

of Aberdeen, Aberdeen

Maternity Hospital,

Aberdeen, UK.

ashok@abdn.ac.uk

\section{Conclusion}

In women seeking emergency contraception within 72 hours after an episode of unprotected sexual intercourse, mifepristone given in a $100 \mathrm{mg}$ dose was a more effective post-coital contraceptive than the Yuzpe regimen.

*p value calculated from data in article.

\section{COMMENTARY}

Effective, well tolerated, and accessible emergency contraception is needed to avoid unwanted pregnancies after unprotected intercourse. To date, research on mifepristone has been limited to studies comparing various dosages $^{1}$ and studies comparing a high dose $(600 \mathrm{mg})$ with the Yuzpe regimen. ${ }^{23}$ Ashok et al have done the first randomised controlled trial comparing lower dose mifepristone $(100 \mathrm{mg})$ with the Yuzpe regimen for emergency contraception.

This study's strengths include its randomised design and follow up of $>95 \%$ of the sample for the primary outcome. However, data about side effects and patient acceptability were only available for $62 \%$ of the sample. The fact that patients were not blinded to treatment may also have influenced patient reporting of these 2 secondary outcomes (especially because the Yuzpe regimen involved 4 tablets as opposed to a half tablet of mifepristone).

Given previous study findings showing that dosages of 10 , 50 , and $600 \mathrm{mg}$ of mifepristone were equally effective in reducing the likelihood of pregnancy, ${ }^{1}$ it would have been ideal to compare a very low dose of mifepristone (eg, $10 \mathrm{mg}$ rather than $100 \mathrm{mg}$ ) to the Yuzpe regimen; however, the drug is currently available only as a $200 \mathrm{mg}$ tablet in the UK where the study was conducted.

What are the clinical implications of this study? Based on these findings, and in countries where it is available, $100 \mathrm{mg}$ of mifepristone is more effective and probably better tolerated than the Yuzpe regimen. However, it is important to keep in mind that mifepristone is controversial because of its association with induced abortion and because it may delay ovulation, which may pose a risk for couples who continue to have unprotected intercourse.

Laurel Satov, RN(EC), BA Primary Health Care Nurse Practitioner/Clinical Supervisor, Addiction Services, Out and About Clinic Hotel Dieu Health Sciences Hospital Niagara St Catharines, Ontario, Canada

1 Task Force on Postovulatory Methods of Fertility Regulation. Comparison of three single doses of mifepristone as emergency contraception: a randomised trial. Lancet 1999;353:697-702.

2 Glasier A, Thong KJ, Dewar M, et al. Mifepristone (RU 486) compared with high-dose estrogen and progestogen for emergency postcoital contraception. N Eng J Med 1992;327:1041-4.

3 Webb AM, Russell J, Elstein M. Comparison of Yuzpe regimen, danazol, and mifepristone (RU486) in oral postcoital contraception. BMJ 1992;305:927-31. 